\title{
Maladaptive behaviors are linked with inefficient sleep in individuals with developmental disabilities
}

\author{
Mohammed R. Lenjavi • Michael A. Ahuja • \\ Paul E. Touchette $\cdot$ Curt A. Sandman
}

Received: 12 November 2009 / Accepted: 23 April 2010/Published online: 9 May 2010

(C) The Author(s) 2010. This article is published with open access at Springerlink.com

\begin{abstract}
The purpose of the current study was to assess the relations between nightly sleep patterns and the frequency of daily maladaptive behavior. Antecedent and consequential relations between sleep patterns and behavior were evaluated with time series analysis. Sleep efficiency and maladaptive behavior were determined for 20 female residents of an institutional care facility for adults with developmental disabilities. Daily maladaptive behavioral data and nightly sleep/awake logs were collected for 4 months for each participant. Efficient sleep patterns were significantly associated with lower frequencies of maladaptive behaviors. All lagged cross-correlations 8 days before and 8 days after an evening of sleep were significant. These findings suggested that inefficient sleep was associated with increased maladaptive behaviors and that the lagged associations reflected a chronic but not an acute linkage between sleep and behavior.
\end{abstract}

Keywords Self-injurious behaviors · Developmental disabilities $\cdot$ Sleep problems $\cdot$ Inefficient sleep

There are well-known consequences of poor sleep in the typically developing population, including depression (Tsuno et al. 2005), obesity (Taheri 2006), hypertension (Gangwisch et al. 2006; Legramante and Galante 2005),

M. R. Lenjavi · M. A. Ahuja $\cdot$ C. A. Sandman $(\triangle)$

Department of Psychiatry \& Human Behavior,

University of California Irvine,

333 City Blvd. West, Suite 1200 ,

Orange, CA 92868, USA

e-mail: casandma@uci.edu

P. E. Touchette

Department of Pediatrics, University of California Irvine,

Orange, CA, USA neurodegenerative disease (Boeve et al. 2007), and mood disorders (Bauer et al. 2006; Lewy et al. 2006). Some studies suggest that sleep disorders, such as insomnia are common in individuals with developmental disorders (Couturier et al. 2005; Didden et al. 2002a, b; Honomichl et al. 2002; Owens et al. 2000; Patzold et al. 1998; Robinson and Richdale 2004; Stores 1999) however the few studies focusing on sleep and its relevance to maladaptive behaviors in individuals with developmental delay are inconclusive. Brylewski and Wiggs (1999) found that individuals with intellectual delay, who had intermittent nightly sleep or a low amount of nightly sleep, displayed significantly more daytime irritability, stereotypy and hyperactivity. A subsequent study (Didden et al. 2002b) reported that children with severe levels of intellectual disability who exhibited daytime behavioral problems including aggression, non-compliance and hyperactivity, also had sleep problems. Symons et al. (2000) determined that individuals with profound mental retardation who exhibited self-injurious behavior (SIB) slept significantly less and had patterns of sleep that were more varied and irregular than a group of profoundly mentally retarded individuals without SIB. In a study investigating the special health care needs of children with developmental delay, Kennedy et al. (2007) found that a group of children with maladaptive behaviors required significantly more health care needs than the control group. Furthermore, the only significant difference in chronic conditions compared to the control group was the statistically significant prevalence of sleep disorders in the group of children with maladaptive behaviors.

The purpose of the current study was to assess the relations between nightly sleep patterns and the frequency of daily maladaptive behavior. Antecedent and consequential relations between sleep patterns and behavior were evaluated with time series analysis. 


\section{Methods}

Data were collected for sleep and behavior patterns of 20 female adults who lived in the same residence hall of a 900-bed residential treatment center for individuals with developmental disabilities. Sleep and behavioral data were collected. Because the patients shared the same residence and staff, the environmental conditions were identical for all subjects and the possible effects of staff reporting bias were consistent. Descriptive information is presented in Table 1 for each subject including age, intellectual levels and medication regimens.

\section{Participants}

Patients ranged from 19 years to 58 years of age $(M=40$, $\mathrm{SD}=9$ ). Measures of intellectual impairment of the participants ranged from profound to mild. A majority of the participants were receiving psychotropic medication. None of the participants were prescribed medication specifically for sleep aid. Participants were included if they had at least one maladaptive behavior that had been identified by the interdisciplinary clinical team and was observed and recorded by the staff.

Data collected

Staff recorded nightly patient activities in "sleep logs" every 15 min starting at 10:45 pm and ending at 6:15 am for 4 months (122 days). Sleep log entries were based on direct observation of each patient at each fifteen-minute interval. If a participant was in bed with eyes closed, then "sleep" was entered for that period of time. Similarly, if a participant was in bed with eyes open, then "awake" was entered for that interval. If participants were out of their beds, then the respective interval data was coded as "awake." The reasons participants were not in bed were idiosyncratic (e.g. toileting, walking hallway) and were not summarized for the analyses presented here. Independent raters coded sleep intervals and maladaptive behavior over the 4 months of the study to ensure the accuracy and reliability of staff observations. Inter-observer (IOA) agreement checks were performed on $10 \%$ of all data collected with $85-100 \%$ agreement between observers. A sleep efficiency index (SEI) was used to obtain

Table 1 Subject demographics

\begin{tabular}{|c|c|c|c|c|c|}
\hline Subject & Age & MR level & IQ & Medications & Maldaptive behaviors \\
\hline 1 & 47 & Profound & 15 & Olanzapine & Banging head, screaming \\
\hline 2 & 19 & Profound & 17 & Olanzapine & Biting others, throwing objects, crying/yelling \\
\hline 3 & 44 & Profound & 13 & $\begin{array}{l}\text { Carbamazepine, Chlorpromazine, Trifluoprazine, } \\
\text { Lithium, Diazepam }\end{array}$ & Pinching self \\
\hline 4 & 34 & Severe & 24 & Carbamazepine, Tegretol, Luvox, Olanzapine & Banging face, biting hand \\
\hline 5 & 42 & Profound & 14 & Divalproex, Mirtazapine & Scratching others \\
\hline 6 & 42 & Severe & 30 & Paroxetine & Hitting others, tense body posture \\
\hline 7 & 37 & Severe & 23 & Haloperidol, Olanzapine, Secobarbitol & Hitting others, banging head \\
\hline 8 & 58 & Profound & 10 & Olanzapine & Destroying items \\
\hline 9 & 45 & Severe & 30 & Haloperidol, Quetiapine & Biting/scratching others, crying, slapping hands \\
\hline 10 & 40 & Profound & 16 & Clonazepam & Hitting, kicking and scratching others \\
\hline 11 & 54 & Profound & 12 & - & Screaming and pacing \\
\hline 12 & 46 & Mild & 51 & Olanzapine & Hitting others, crying, screaming \\
\hline 13 & 50 & Profound & 18 & Phenytoin, Clomipramine, Lithium, Risperidone & $\begin{array}{l}\text { Hitting and scratching others, tearing own } \\
\text { clothes }\end{array}$ \\
\hline 14 & 34 & Mild & - & $\begin{array}{l}\text { Divalproex, Phenytoin, Topiramate, Citalopram, } \\
\text { Ziprasidone }\end{array}$ & Hitting others, scratching others, cursing \\
\hline 15 & 40 & Profound & 12 & Haloperidol & $\begin{array}{l}\text { Pushing, hitting, grabbing others, pulling } \\
\text { other's hair }\end{array}$ \\
\hline 16 & 44 & Profound & 10 & $\begin{array}{l}\text { Diazepam, Pivalproex, Leviteracetam, Phenobarbitol, } \\
\text { Fluoxetine, Olanzapine }\end{array}$ & Banging head, hitting others, head butting \\
\hline 17 & 35 & Severe & 34 & Olanzapine & Banging head, hitting head, kicking self \\
\hline 18 & 33 & Moderate & 40 & Divalproex & Banging arms on hard surfaces, yelling, crying \\
\hline 19 & 27 & Mild & 62 & Fluoxetine, Quetiapine & Striking others \\
\hline 20 & 40 & Severe & - & $\begin{array}{l}\text { Paxil, Resperidone, Naltrexone, Olanzapine, } \\
\text { Venlafaxine, Tegratol }\end{array}$ & Picking at skin, screaming, pushing others \\
\hline
\end{tabular}


a standardized ratio per subject per night. The index was a modified version of the one reported by Carr and Neumann (1999), calculating the total time asleep minus any other activities observed in or out of bed.

The sleep efficiency index (SEI) was calculated using the following formula:

\section{$\frac{[\text { \#Intervals Asleep }]-[\# \text { of Intervals Awake }]}{[\text { Total Number of Observed Intervals }]}$}

Daytime behaviors

The frequency of daytime maladaptive behaviors was collected by direct observation of the participants from 6:15 am to $10: 45 \mathrm{pm}$ each day for 4 months (122 days). Staff recorded only behaviors identified and defined for each subject by the interdisciplinary clinical team for the duration of the study. Maladaptive behaviors for the subjects in this study included but were not limited to
Fig. 1 a Mean SEI for each individual's data across 4 months ranked from highest to lowest and $\mathbf{b}$ matched mean behavior for all participants across the same 4 months

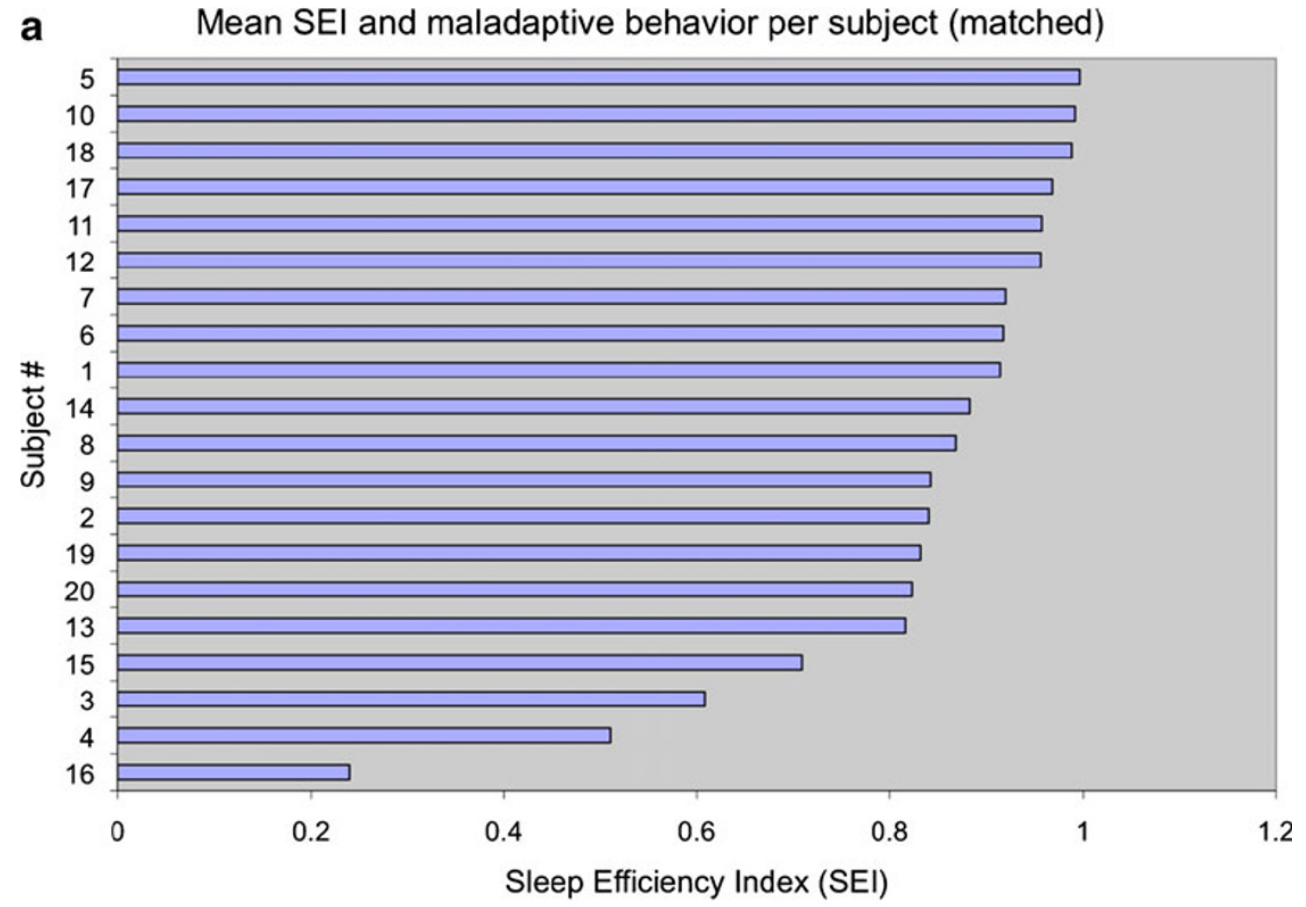

b

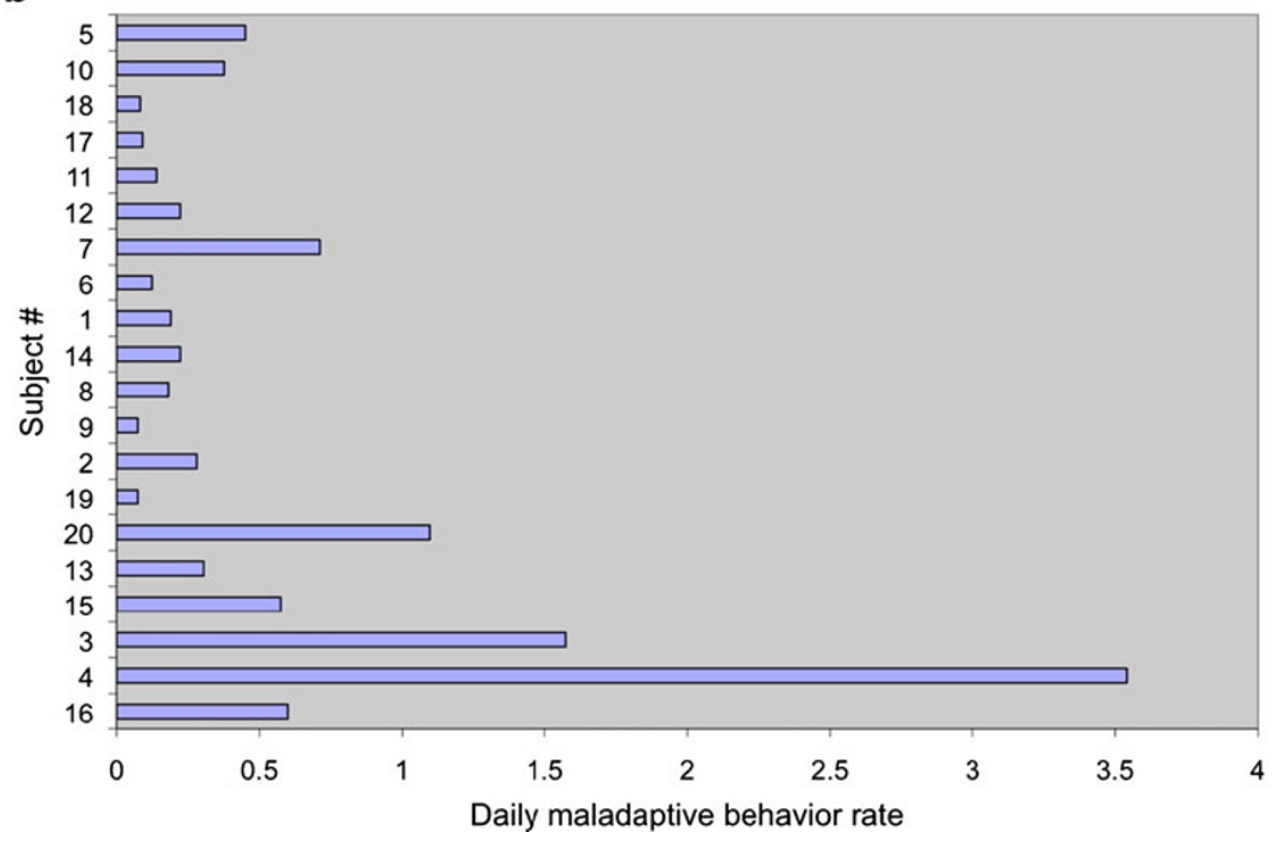


hitting self, hitting others, banging head, property damage, screaming, and smearing (see Table 1).

Data analyses

Means for each individual, collapsed across the 4 months, were calculated for both SEI and maladaptive behavior counts. These were then log transformed to normalize the distribution and compared using Pearson's productmoment correlation coefficients. In order to investigate the temporal aspects of relations between sleep and daytime behavior, lagged cross-correlations were performed for the log-transformed means for all subjects, distributed across the 4 months. These analyses compared mean SEI for a given night with mean maladaptive behavior for the each of the 8 days before and the 8 days after an evening of sleep recordings.

\section{Results}

Mean SEI ratios for individual participants ranged from .24 to $.99(M=.83, \mathrm{SD}=.19)$ and are presented in Fig. 1a. Mean maladaptive behavioral counts for the same individuals during the same period ranged from .07 to 3.5 per day $(M=.55, \mathrm{SD}=.80)$ and are presented in Fig. 1b.

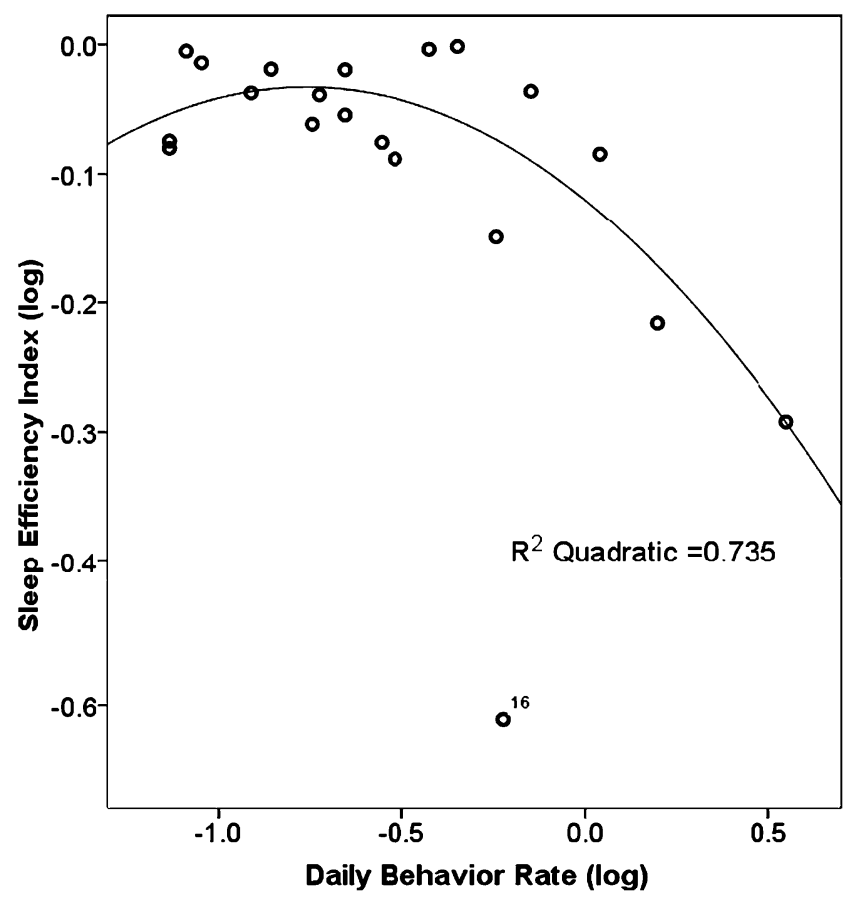

Fig. 2 Sleep efficiency and maladaptive behaviors are highly correlated at lag +1 . The deviant subject (subject 16) is highlighted
Correlations and lagged correlations

Linear analysis indicated that individuals with efficient sleep patterns (i.e. high ratios) had significantly lower frequencies of maladaptive behavior the day preceding a night of sleep recording (lag +1$)(r=-.49, p=.028)$. As apparent in Fig. 2, one subject had a highly deviant sleep efficiency index $(M=.24$; approximately 3 SD's below the mean after log transformation). Subsequent analyses with this subject removed improved the association between SEI and maladaptive behavior (lag $+1 r=-.70, p=.001)$. The quadratic solution with subject 16 removed accounted for more variance than the linear relation between sleep efficiency and behavior (49\% vs. $74 \%$ ) as illustrated in Fig. $2\left(\mathrm{r}^{2}=.74, p=.001\right)$. Eight of the 20 subjects had selfinjurious behaviors (SIB). There were no significant differences in sleep efficiency between individuals with SIB compared to those with other maladaptive behaviors $t(7.4)=$ $1.4, p=.19$. There was also no difference in frequency of maladaptive behaviors between individuals with SIB and those with other maladaptive behaviors $t(9.2)=-1.6, p=.13$. There were no significant correlations between age and SEI $(r=-.02, p=.94)$ and between age and frequency of maladaptive behavior $(r=-.02, p=.93)$.

Lagged cross-correlations were performed to examine the temporal relations between sleep efficiency and maladaptive behavior. In Table 2 , both positive and negative

Table 2 Lagged cross-correlations in \pm 8 days

\begin{tabular}{lcc}
\hline Lag number & R value & Significance \\
\hline-8 & -.72 & .000 \\
-7 & -.72 & .000 \\
-6 & -.72 & .001 \\
-5 & -.72 & .001 \\
-4 & -.71 & .001 \\
-3 & -.71 & .001 \\
-2 & -.70 & .001 \\
-1 & -.70 & .001 \\
Concurrent & -.70 & .001 \\
1 & -.70 & .001 \\
2 & -.71 & .001 \\
3 & -.72 & .001 \\
4 & -.72 & .000 \\
5 & -.72 & .000 \\
6 & -.72 & .000 \\
7 & -.72 & .001 \\
8 & -.71 & .001 \\
\hline
\end{tabular}

Lagged cross correlations between log of sleep efficiency ratios and $\log$ of mean maladaptive behaviors for 8 days before and 8 days after the target evening of sleep. Negative correlations indicate that poor sleep is related to problem behaviors and that the relation between these variables is chronic and not acute 
lags are presented. The negative lags reflect the relation between sleep and subsequent behavior for 8 days and the positive lags indicate the relation between behavior and subsequent nights of sleep for 8 days. For example, the lag at -8 reflects the relation $(-0.72)$ between maladaptive behavior on the target day and the quality of sleep 8 days earlier. The relation between sleep and behavior labeled as concurrent lag reflects the measures of sleep quality and maladaptive behavior for the same day. All lagged correlations between sleep quality and maladaptive behavior were statistically significant and nearly identical (see Table 2).

There were no changes in medications or treatment plans for any subjects during the study. However, we cannot rule out the possibility that there were interventions that may have introduced a consistent bias in the expression of behavior during the period of observation. To indirectly assess this possibility, we performed autocorrelations of daily maladaptive behavior counts for each subject across the 4 months of the study. A significant proportion $(p<0.05$; binomial expansion) of subjects had statistically significant autocorrelations of successive maladaptive behaviors. This result indicates that behavioral counts had a consistent daily pattern for a significant number of subjects and is inferential evidence that there were no interventions or intrusions during the course of the study that altered the consistent pattern of behavior.

\section{Discussion}

The finding in the current study of a significant relation between quality of sleep and maladaptive behavior among individuals with developmental delay is consistent with a small previous literature. There are several reports that individuals with behavioral problems or with severe mental retardation exhibit sleep disturbance (Didden et al. 2002b; Dominick et al. 2007; DeLeon et al. 2004). One retrospective study of individuals with specific maladaptive behaviors such as self-injury found that they had significantly more varied and irregular patterns of sleep than matched controls without specific behavioral problems (Symons et al. 2000). Our findings, utilizing a prospective design and $3720,15 \mathrm{~min}$ observation intervals for each subject, complements previous findings of a significant association between patterns of poor sleep and expression of a spectrum of maladaptive behaviors. There was no distinction in (SEI) sleep profiles between the small subgroup of subjects with SIB and those with other forms of maladaptive behaviors.

In addition to the significant correlation between concurrent maladaptive behaviors and sleep efficiency over a four-month period, the significant lagged correlations for 8 days before and after the target day suggests that the reciprocal relations between sleep and behavior are not acute. These findings indicate that inefficient sleep patterns do not increase the risk of maladaptive behavior only on the following day. Conversely, maladaptive behaviors during the day do not predict inefficient sleep only later that night. Instead, these findings suggest that there is a "chronic" relation between poor sleep and maladaptive behavior. It appears from our findings that individuals with maladaptive behaviors tend to have less efficient sleep patterns generally. The choice of \pm 8 days lag was arbitrary but was sufficient to examine and eliminate one implicit hypothesis of this study, specifically that a poor night's sleep would increase the risk of immediate or subsequent behavioral problems.

One interesting outcome of this study was the identification of an outlier. She was identified by her deviant sleep patterns (over three standard deviations from the group mean) and the relative absence of behavioral problems. This woman (subject 16) was 44 years old, profoundly mentally retarded, non-verbal, semi-ambulatory, and slept very little at night. We discovered that this woman slept most of the day and therefore did not present as an individual with behavioral problems. Although behaviors such as hitting others, head butting and banging her head against surfaces were identified as behavioral problems, not many counts were recorded because she napped most of the day. Figure 3 illustrates the subject's erratic sleep pattern (a) over 18 months of observation versus a subject with consistent sleep (b). Thus the absence of an association between her poor sleep and behavior may be attributable to a disturbed circadian sleep cycle.

\section{Limitations}

Direct observations of individuals in their natural setting preclude the implementation of experimental controls commonly seen in laboratory studies of sleep. Conventional laboratory sleep studies include measures that permit the ability to precisely define sleep and stages of sleep including: restlessness, REM cycles, perfusion, or intermittent awakening. These measures were not possible to implement in such a large sample of conserved subjects, with multiple observations conducted simultaneously in a residential facility. For some questions there are clear advantages to laboratory studies, however our naturalistic observation design provided an opportunity to collect 122 continuous days of sleep and behavior from subjects residing in the same environment and assess the linkage between daytime behavior and sleep. Although the typical controls for physiological measures of sleep were not available, the large sample, the dense sampling period, 
Fig. 3 Sleep versus Awake patterns per interval for subject 16 (a) contrasted with patterns of a subject with consistent sleep (b) and low frequency of maladaptive behaviors
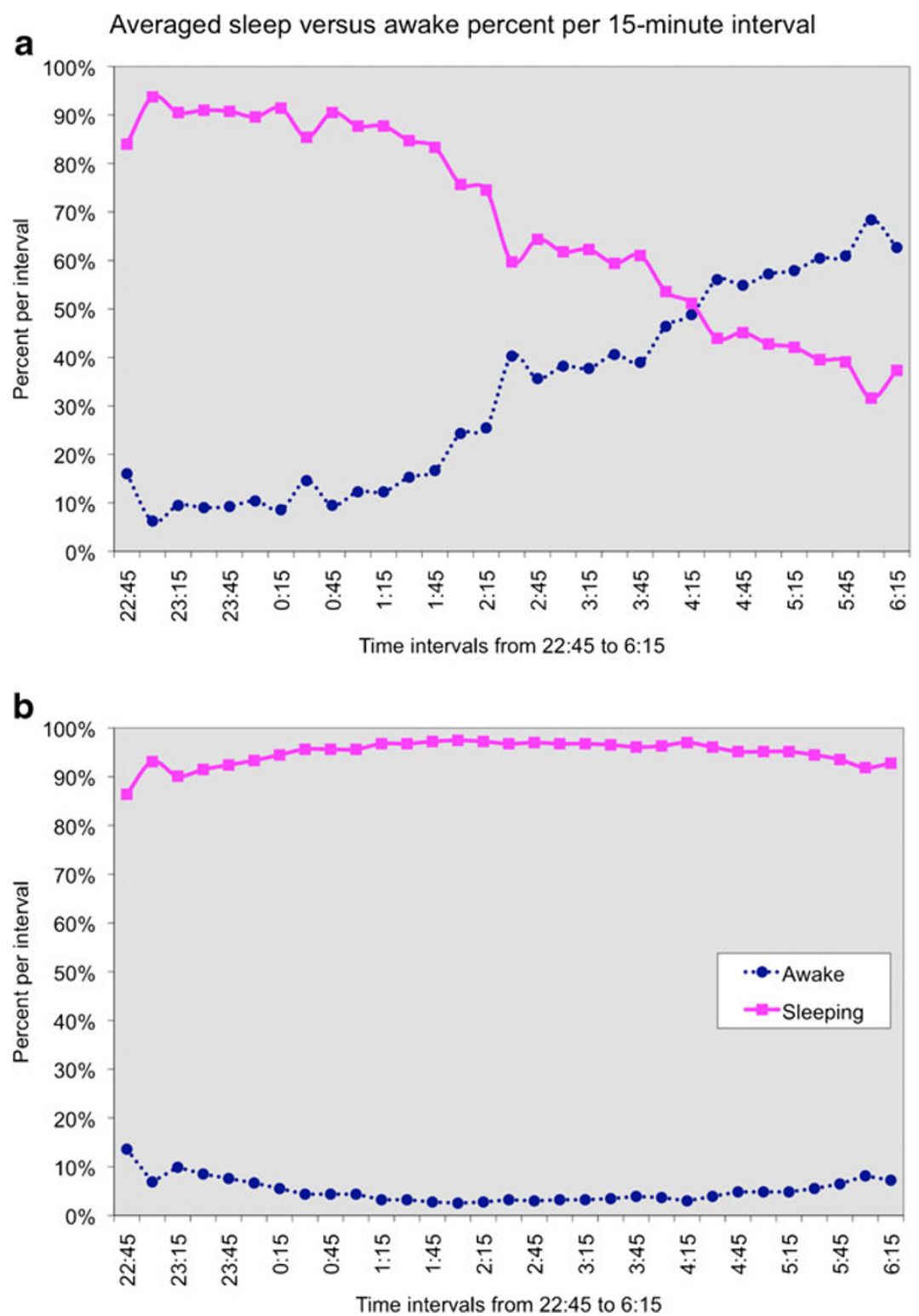

and the comparable environment for each subject provided controls and power usually not possible in studies of sleep. Moreover, it is unlikely that obtaining representative measures of sleep in a laboratory setting from this population of individuals would be feasible due to poor compliance and inability to comprehend instructions or discomfort experienced by introducing the subject to a sleep laboratory environment.

\section{Conclusions}

Significant relations between disturbances in sleep efficiency and disorders such as depression, obesity and heart disease have been investigated in numerous studies in typical populations (Bauer et al. 2006; Gangwisch et al. 2006; Lewy et al. 2006; Taheri 2006; Tsuno et al. 2005). The current study adds to a small literature indicating that sleep disorders are significantly associated with maladaptive behaviors among individuals with developmental disabilities. It was surprising that the relation between sleep and behavior was not temporally contingent. These new findings suggest a chronic link between sleep and maladaptive behavior. Establishing a link between sleep and behavioral problems in this population invites both further studies and clinical interventions to discover possible causal relations. 
Open Access This article is distributed under the terms of the Creative Commons Attribution Noncommercial License which permits any noncommercial use, distribution, and reproduction in any medium, provided the original author(s) and source are credited.

\section{References}

Bauer M, Grof P, Rasgon N, Bschor T, Glenn T, Whybrow PC. Temporal relation between sleep and mood in patients with bipolar disorder. Bipolar Disord. 2006;8(2):160-7. doi:10.1111/ j.1399-5618.2006.00294.x.

Boeve BF, Silber MH, Saper CB, Ferman TJ, Dickson DW, Parisi JE. Pathophysiology of REM sleep behaviour disorder and relevance to neurodegenerative disease. Brain. 2007;130(Pt 11):2770-88. doi:10.1093/brain/awm056.

Brylewski J, Wiggs L. Sleep problems and daytime challenging behaviour in a community-based sample of adults with intellectual disability. J Intellect Disabil Res. 1999;43(Pt 6):504-12. doi:10.1046/j.1365-2788.1999.00234.x.

Carr EG, Neumann JK. Graphic sleep monitoring: a clinical program to improve sleep in residents with mental retardation. J Dev Phys Disabil. 1999;11(2):91-103. doi:10.1023/A:1021838902763.

Couturier JL, Speechley KN, Steele M, Norman R, Stringer B, Nicolson R. Parental perception of sleep problems in children of normal intelligence with pervasive developmental disorders: prevalence, severity, and pattern. J Am Acad Child Adolesc Psychiatry. 2005;44(8):815-22. doi:10.1097/01.chi.0000166377.22651.87.

DeLeon IG, Fisher WW, Marhefka JM. Decreasing self-injurious behavior associated with awakening in a child with autism and developmental delays. Behav Interv. 2004;19(2):111-9. doi:10.1002/bin.154.

Didden R, Curfs LM, van Driel S, de Moor JM. Sleep problems in children and young adults with developmental disabilities: home-based functional assessment and treatment. J Behav Ther Exp Psychiatry. 2002a;33(1):49-58. doi:10.1016/S0005-7916(02)00012-5.

Didden R, Korzilius H, van Aperlo B, van Overloop C, de Vries M. Sleep problems and daytime problem behaviours in children with intellectual disability. J Intellect Disabil Res. 2002b;46(Pt 7):537-47. doi:10.1046/j.1365-2788.2002.00404.x.

Dominick KC, Davis NO, Lainhart J, Tager-Flusberg H, Folstein S. Atypical behaviors in children with autism and children with a history of language impairment. Res Dev Disabil. 2007;28 (2):145-62. doi:10.1016/j.ridd.2006.02.003.

Gangwisch JE, Heymsfield SB, Boden-Albala B, Buijs RM, Kreier F, Pickering TG, et al. Short sleep duration as a risk factor for hypertension: analyses of the first National Health and Nutrition
Examination Survey. Hypertension. 2006;47(5):833-9. doi:10.1161/01.HYP.0000217362.34748.e0.

Honomichl RD, Goodlin-Jones BL, Burnham M, Gaylor E, Anders TF. Sleep patterns of children with pervasive developmental disorders. J Autism Dev Disord. 2002;32(6):553-61. doi:10.1023/A:1021254914276.

Legramante JM, Galante A. Sleep and hypertension: a challenge for the autonomic regulation of the cardiovascular system. Circulation. 2005;112(6):786-8. doi:10.1161/CIRCULATIONAHA. 105.555714

Kennedy CH, Juarez AP, Becker A, Greenslade K, Harvey MT, Sullivan C, et al. Children with severe developmental disabilities and behavioral disorders have increased special healthcare needs. Dev Med Child Neurol. 2007;49(12):926-30. doi:10.1111/ j.1469-8749.2007.00926.x.

Lewy AJ, Lefler BJ, Emens JS, Bauer VK. The circadian basis of winter depression. Proc Natl Acad Sci USA. 2006;103:7414-9. doi:10.1073/pnas.0602425103.

Owens JA, Maxim R, Nobile C, McGuinn M, Msall M. Parental and self-report of sleep in children with attention-deficit/hyperactivity disorder. Arch Pediatr Adolesc Med. 2000;154(6):549-55.

Patzold LM, Richdale AL, Tonge BJ. An investigation into sleep characteristics of children with autism and Asperger's Disorder. J Paediatr Child Health. 1998;34(6):528-33. doi:10.1046/j.14401754.1998.00291.x.

Robinson AM, Richdale AL. Sleep problems in children with an intellectual disability: parental perceptions of sleep problems, and views of treatment effectiveness. Child Care Health Dev. 2004;30 (2):139-50. doi:10.1111/j.1365-2214.2004.00395.x.

Stores G. Children's sleep disorders: modern approaches, developmental effects, and children at special risk. Dev Med Child Neurol. 1999;41(8):568-73. doi:10.1017/S001216229900119X.

Symons FJ, Davis ML, Thompson T. Self-injurious behavior and sleep disturbance in adults with developmental disabilities. Res Dev Disabil. 2000;21(2):115-23. doi:10.1016/S0891-4222 (00)00028-7.

Taheri S. The link between short sleep duration and obesity: we should recommend more sleep to prevent obesity. Arch Dis Child. 2006;91(11):881-4. doi:10.1136/adc.2005.093013.

Tsuno N, Besset A, Ritchie K. Sleep and depression. J Clin Psychiatry. 2005;66(10):1254-69. doi:2006-10343-008.

This study is supported by award \#HD048947 from the National Institutes of Health to CAS. The authors are grateful for the assistance of Aaron Kemp, Shervin Bazmi, Karen Gordon and the staff of Residence 43 at Fairview Developmental Center. 